SHS Web of Conferences 2, 00027 (2012)

DOI: $10.1051 /$ shsconf $/ 20120200027$

(C) Owned by the authors, published by EDP Sciences, 2012

\title{
Studies of medicines use by consumers
}

\author{
I. Salmane-Kulikovska and S. Dobelniece
}

Rīga Stradinš University, Latvia

\begin{abstract}
One of the main aims of medicines' use studies is to ensure rational use of them. Different types of medicines use studies exist - there are studies of medicines supply, consumption, behavior of medicines users and prescribers (advisers). The aim of the current study is to find common patterns or problems regarding use of medicines, as well as the factors influencing medicines' use patterns, and also apply the findings to the sociological theory. The study was implemented by making an insight into reviews of medicines' use and theoretical literature. A range of analysis-levels is available, depending on the scope of a study. Common patterns or problems of medicines' use within these levels have been pointed out by the studies - non-compliance to the medicines' information, self-medication with prescription medicines, polypharmacy, unsafe use of herbal medicines, overuse of injections, use of nonessential combination medicines, and use of needlessly expensive medicines. The studies suggest several determinants of medicines use - demographic and socio-economic factors, socio-psychological factors, health status, cultural factors, and information channels. From the point of view of the sociological theory it is possible to classify all these factors according to the notions of "micro", "macro", "objectivity" and "subjectivity", as well as by different perspectives of rationality - objective rationality (medical perspective) and subjective rationality (user's perspective).
\end{abstract}

Key words: medicines, rational use of medicines, medicines' use determinants

Important aim of medicines use studies is to ensure that medicines are used rationally-appropriately to the clinical needs, in doses that meet individual requirements, for an adequate period of time and at the possible lowest cost (WHO, 2002). Rational use of medicines is a key concept in almost all policies regarding health service quality and management.

Medicines use studies have been initiated by the "thalidomide disaster". ${ }^{1}$ Since that time lots of researches have been performed to explore medicines use, involving a number of organizations, like WHO, INRUD (International Network for Rational use of drugs), European Drug Utilization Research Group, etc. Depending of the research aims, medicines use studies may be classified into five broad categories (Capella, 1993; 66-72):

1. Medicines supply studies.

2. Studies of consumption (qualitative and quantitative).

3. Studies of prescription and prescribing.

4. Studies of patient compliance or non-compliance.

5. Ad hoc (designed for particular needs) studies.

Although these types possess distinctive scopes, all of them can to some extent demonstrate patterns and problems of medicines use by consumers.

Use of medicines is a multi-dimensional subject, therefore an insight into pharmacology, epidemiology and also in the social sciences is essential to embrace all dimensions (Haaijer-Ruskamp, Hemminki, 1993; 97). Use of medicines is an important component of individual's illness behavior

This is an Open Access article distributed under the terms of the Creative Commons Attribution License 2.0, which permits unrestricted use, distribution, and reproduction in any medium, provided the original work is properly cited.

${ }^{1}$ Thalidomide, a sedative remedy was introduced in 1950ies. In 1961 it was withdrawn from the market after being found to be a cause of birth defects of newborn children, whose mothers had used this medicine during pregnancy. 


\section{SHS Web of Conferences}

(Scambler, 2008; 41-54), and illness behavior is closely related to how individuals perceive illness, these interpretations are derived from the society or, in other words, they are "socially constructed", and it is the task of medical sociology to investigate where they arrive from (Armstrong, 1983; 2). Social sciences and sociological theory may help understand what factors influence illness perception and behavior, including use of medicines by consumers.

The aim of this study is to make insight into studies and reviews, targeted to find common patterns or problems of medicines' use, factors influencing individual's behavior in respect to medicines use, as well as to apply these findings to the sociological theory.

\section{Materials and methods}

Theoretical materials include WHO manual "How to Investigate the Use of Medicines by Consumers" (Hardon, Hodgkin, Fresle, 2004), WHO database review (679 studies conducted in 97 developing and transitional countries), containing results from all studies in the WHO database published up to the end of 2006 (World Health Organization, 2009), WHO manual "Drug Utilization Studies: Methods and Uses" (Dukes, 1993). Empirical sources include results of the studies, posted in academic data basis (SAGE, EBSCO and Science Direct) since 1980. The summary of the findings is analyzed in the context of the sociological theory, referring to the works of George Ritzer, William Cocherham, and other author.

\section{Results and discussion}

\section{Common patterns or problems of medicines' use}

Depending on a particular type of medicines use studies, it is possible to refer to different levels (le Grand, Hogerzeil, Haaijer-Ruskamp, 1999; 90; Hardon, Hodgkin, Fresle, 2004; 2-7):

1. Household and community level.

2. Health service institution level.

3. National level.

4. International level.

Selection of medicines use patterns may be attributed to all these levels, either separately, or together. Common patterns or problems of medicines' use have been obtained as the result of analysis of numerous studies in all these levels (Hardon, Hodgkin, Fresle, 2004; World Health Organization, 2009; le Grand, Hogerzeil, Haaijer-Ruskamp, 1999):

1. Medicines are not used according to the prescriber's indications or written medicines information - for too long or too short period of time, not following instructions or written medicines information, taking inappropriate dosage, etc.

2. Self-medication with prescription medicines and wrong use of antibiotics. The most widespread patterns of inappropriate use of antibiotics are cases of treatment of upper respiratory tract infections and diarrhoea. The evidence suggests that patterns of medicines use in treatment of these diseases have deteriorated over time, and inadequate prescribing and advising patterns at the presence of these diseases are present in every geographic region of the world.

3. Polypharmacy - the number of medicines used simultaneously is larger than necessary, following the principle "a pill for every ill". Overconsumption of medicines concerns mostly painkillers and cough and cold preparations.

4. Unsafe use of herbal medicines.

5. Overuse of injections, concerning mainly developing countries with the widespread beliefs that injections are more effective than orally administered medicines. 
Int. Conf. SOCIETY. HEALTH. WELFARE; Congr. of Rehabilitation Doctors of Latvia

6. Use of non-essential combination medicines.

7. Use of needlessly expensive medicines. Due to the lack of knowledge, branded medications are preferred, containing the same active substance as their cheaper equivalents - generic medicines.

From the point of view of rationality these patterns of inappropriate medicines use can be denoted also as the patterns of "non-rational" or "irrational" use from medical perspective. Another perspective consumers' perspective exists, and this perspective is important when analyzing the concept "rational use of medicines", because "rational" in a medical sense may not be rational for a consumer, and vice versa. As the researchers denote it, "for the consumer, a rationality of using a medicine is based on (re)interpretations of its value for a daily life, influenced by cultural perceptions and economic conditions" (le Grand, Hogerzeil, Haaijer-Ruskamp, 1999; 89).

\section{Factors influencing use of medicines}

Depending on the aims and scopes, different authors propose several determinants, having impact on the patterns of medicines use. Influence of demographic factors, such as age, sex, social class on use of medicines is revealed by a number of studies (Birchley, Conroy, 2001; Birchley, Conroy, 2002; Daban et al., 2010; Johnson, Pope, 1983; Tobi et al., 2003; Horne et al., 2004). Socio-economic factors have been proven to have an impact on choice and use of medicines (Birchley, Conroy, 2002; Daban et al., 2010; Johnson, Pope, 1983; Nielsen, Hansen, Rasmussen, 2003; Tobi et al., 2003; Horne et al., 2004). A number of studies propose socio-psychological factors, such as tendency towards self-medication, level of concern with healthcare matters (Johnson, Pope, 1983), health beliefs, illness perception, parental example, depression, anxiety, personal traits (Tobi et al., 2003; Birchley, Conroy, 2002; Crane, Martin, 2002; Horne et al., 2004), as determinants of medicines' use. Health status (objective health status, severity of disease, self-rated or perceived health) has been mentioned as one of the determinants (Daban et al., 2010; Johnson, Pope, 1983; Tobi et al., 2003). Several studies have examined how the particular culture influences patterns of medicines use (Yee, 2004; Horne et al., 2004). The amount of information users of medicines face nowadays is immense, and the content of the information shapes medicines' use patterns differs to a considerable extent. There is information, aimed at the selling of medicines (advertising, activities of the pharmaceutical sector, etc.), and also informative and explanatory information, provided by government, NGOs, healthcare representatives, etc. (Birchley, Conroy, 2002; Busfield, 2010; Horne et al., 2004).

\section{Sociological theory}

From the point of view of the sociological theory any social phenomenon is subjected to the influence of two levels - micro and macro. Some authors also refer to meso level (Smelser, 1997). Micro-level theories include symbolic interaction theory, phenomenology and exchange theory, and macro-level theories involve structural functionalism, conflict theory, "cultural determinism", macrostructuralism, network theory, ecologism and structuralism (Ritzer, 2008; 374-375). The task to find a link between these levels certainly is one of the most important tasks of sociological theory nowadays (Tsekeris, Lydaki, 2011; 67; Ritzer, 2008).

Medical sociology, as a sub discipline of the larger discipline of sociology (Cockerham, 2007; 41 ), is the study of the social causes and consequences of health and illness (Ibid, 32). Similarly to the general sociological theory this discipline has experienced several shifts of the dominating theoretical paradigm - from macro-level theories, like structural functionalism, to micro-level theories, like symbolic interaction theory and constructionism (Ibid, 25-48). The dominating theoretical paradigm in medical sociology is now social constructionism. This paradigm claims that health and illness are socially constructed, and health behavior is shaped by cultural norms and values, influenced by interaction with other people, beliefs and understandings of health and illness (Ibid, 45). It is meanwhile 


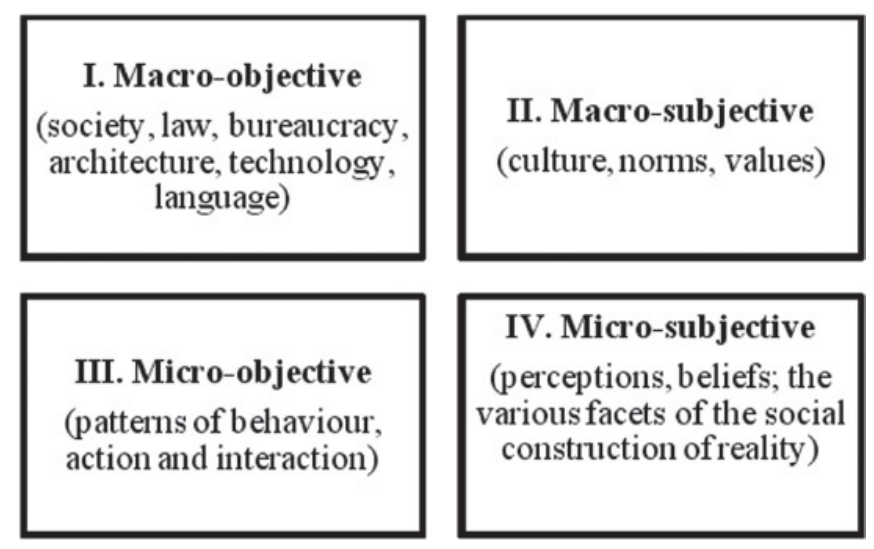

Figure 1. Ritzer's Major Levels of Social Analysis (adapted) (Ritzer, 2008; 377).

noted that structural effects have underestimated impact on individual's behavior; therefore a more comprehensive approach is required in the discipline of medical sociology to interpret the behavior of an individual (Ibid, 48).

One of the significant contributions made to finding a comprehensive approach in general sociological theory is made by the sociologist George Ritzer, proposing integration of micro and macro levels of sociological analysis. The scheme proposed by Ritzer (Figure 1) denies exclusive importance of each separate level, but claims, that both these levels are equally important when performing sociological analysis. Additional notions - objectivity and subjectivity, are added declaring that all social phenomena are also either subjective or objective and being mutually interconnected (Figure 1). Objective indicators, existing regardless of an individual's own perception, are education, occupation, income, wealth, physical and mental health, etc. Subjective indicators are related to individual's own perception and subjective assessment of different factors, such as social status, health, etc. (Karvonen, Rahkonen, 2011; Noll, 2000). These principles may be equally applied to the theory of medical sociology, encompassing use of medicines.

As the sociologists have noted, two types of rationality exist - subjective and objective rationality, and all types of action, performed by an individual, possess an element of subjectivity (Giddens, 1984; Brubaker, 1984; Vēbers, 2004). Healthcare system demands have to be considered from the point of view of the medical perspective, based on objective rationality (le Grand, Hogerzeil, Haaijer-Ruskamp, $1999 ; 89$ ). Consumers' subjective rationality is related to the meaning they attribute to medicines (van der Geest, Whyte, 1989).

\section{Conclusions}

Common patterns or problems regarding use of medicines have been pointed out - non-compliance to the medicines' information, self-medication with prescription medicines, polypharmacy, unsafe use of herbal medicines, overuse of injections, use of non-essential combination medicines, and use of needlessly expensive medicines.

Patterns of medicines have a number of determinants shaping these patterns:

1. Demographic and socio-economic factors (age, sex, ethnicity, education, family size, education, family income, social class, price).

2. Socio-psychological factors (disease perception, beliefs).

3. Health status (physical, mental health, self-assessment of health). 
Int. Conf. SOCIETY. HEALTH. WELFARE; Congr. of Rehabilitation Doctors of Latvia

4. Cultural factors (religion, values, beliefs, traditions, parental example, social roles).

5. Information channels (lay, experts' advice, mass media).

According to the sociological theory these factors can be classified according to the notions of "micro", "macro", "objectivity" and "subjectivity", though it is not possible to draw strict borders between these notions. Generally micro level analysis pertains to small-scale settings, and in the context of medicines use analysis refers to objective indicators - demographic, socio-economic, objective health status, and perception of an individual (subjective factors), including subjective health status and illness perception. Macro level analysis take into account objective factors - social conditions, systems, networks (public discourses, information channels, impact of the pharmaceutical industry, laws, rules, resources, policies (reimbursement schemes, etc.), consumer advocacy, access to medicines, social practices, etc.), and subjective factors - culture, norms, values. Two different perspectives have to be taken into account when analyzing use of medicines - medical perspective (objective rationality) and also consumers' perspective (subjective rationality).

Although common patterns or problems of medicines' use have been summarized, it has been noted, that these patterns cannot be considered universal, as they may differ, depending on the particular area. Studies of medicines use patterns and determinants have to be made by listing research criteria, selecting hypothesis and examining them within the local context.

\section{Limitations of the study}

The current study was not aimed at the review of all the medicines use studies implemented within the particular time period. As the result of the insight into the reviews of the completed studies, common patterns and determinants of medicines' use were drawn out, and these findings were tailored to the sociological theory, revealing additional insights that may enrich the scope of the medicines' use analysis.

\section{References}

[1] Armstrong, D. (1983) An Outline of Sociology as Applied to Medicine. Bristol: Wright.

[2] Birchley, N., Conroy S. (2001) Over the Counter Medicines in Childhood: Issues and Concerns. A Narrative Review of the Literature. Paediatric and Perinatal Drug Therapy 4, 4, p. 161-167.

[3] Birchley, N., Conroy S. (2002) Parental Management of Over-the-counter Medicines. Paediatric Nursing 14, 9, p. 24.

[4] Brubaker, R. (1984) The Limits of Rationality: An Essay on the Social and Moral Thought of Max Weber. London: George Allen \& Unwin.

[5] Busfield, J. A. (2010) Pill for Every Ill': Explaining the Expansion in Medicine Use. Social Science \& Medicine, 70, p. 934-941.

[6] Capella, D. (1993) Descriptive Tools and Analysis. Vol. European Series 45. In Drug Utilization Studies: Methods and Uses, by M.N.G. Copenhagen: WHO Regional publications.

[7] Cockerham, W.C. (2007) Social Causes of Health and Disease. Cambridge: Polity Press.

[8] Crane, C., Martin, M. (2002) Adult Illness Behaviour: the Impact of Childhood Experience. Personality and Individual Differences (Elsevier) 32, p. 785-798.

[9] Daban, F. et al. (2010) Social Determinants of Prescribed and Non-prescribed Medicine Use. International Journal for Equity in Health 9, 12, p. 1-11.

[10] Dukes, M.N.G. (1993) Drug Utilization Studies: Methods and Uses. Vol. 45. Copenhagen: WHO Regional Publications.

[11] Giddens, A. (1984) The Constitution of the Society: Outline of a Theory of Structuration. Berkeley: University of California Press. 


\section{SHS Web of Conferences}

[12] Haaijer-Ruskamp, F.M, Hemminki, E. (1993) The Social Aspects of Drug Use. Vol. European series No.45. In Drug Utilization Studies: Methods and Uses. Copenhagen: WHO Regional publications.

[13] Hardon, A., Hodgkin, C., Fresle, D. (2004) How to Investigate the Use of Medicines by Consumers. Amsterdam: WHO, University of Amsterdam.

[14] Horne, R., Graupner, L., Frosta, S., Weinman, J., Wright, S.M., Hankins, M. (2004) Medicine in a Multi-Cultural Society: the Effect of Cultural Background on Beliefs about Medications. Social Science \& Medicine (Elsevier), 59, p.1307-1313.

[15] Johnson, R.E., Pope, C.R. (1983) Health Status and Social Factors of Nonprescribed Drug Use. Medical care 21,2 , p. 225-233.

[16] Karvonen, S., Rahkonen, O. (2011) Subjective Social Status and Health in Young People. Sociology of Health and Illness 33, 3, p. 372-383.

[17] le Grand, A., Hogerzeil, H.V., Haaijer-Ruskamp, F.M. (1999) Intervention Research in Rational Use of Drugs: A Review. Health Policy and Planning 14, 2, p. 89-102.

[18] Nielsen, M.W., Hansen, E.H., Rasmussen, N.K. (2003) Prescription and Non-prescription Medicine use in Denmark: Association with Socio-economic Position. European Journal of Clinical Pharmacology 59, 677-684.

[19] Noll, H.-H. (2011) Social Indicators and Social Reporting: The International Experience. 2000. http://www.ccsd.ca/noll1.html

[20] Ritzer, G. (2008) Modern Sociological Theory. 7th edition. Boston: McGraw-Hill.

[21] Scambler, G. (2008) Health and Illness Behaviour. Chap. 3. In Sociology as Applied to Medicine. Edinburgh, London, New York, Oxford: Sauders Elsevier.

[22] Smelser, N.J. (1997) Problematics of Sociology: The Georg Simmel Lectures, 1995. Los Angeles, London: University of California Press.

[23] Tobi, H., Meijer, W.M., Tuinstra, J., de Jong ven den Berg, L.T.W. (2003) Socio-economic Differences in Prescription and OTC Drug Use in Dutch Adolescents. Pharm World Sci 25, 5, p. 203-206.

[24] Tsekeris, C., Lydaki, A. (2011) The Micro-Macro Dilemma in Sociology: Perplexities and Perspectives. Sociologija LIII, 1, p. 67-81.

[25] van der Geest, S., Whyte, S.R. (1989) The Charm of Medicines: Methaphors and Metonyms. Medical Anthropology Quaterly 3, 4, p. 345-367.

[26] Vēbers, M. (2004) Reliğijas socioloǵija. Rīga: LU Filozofijas un socioloǵijas institūts.

[27] WHO. (2002) Promoting Rational Use of Medicines: Core Components. WHO Policy perspectives of medicines, Geneva: WHO.

[28] World Health Organization, WHO. (2009) Medicines Use in Primary Care in Developing and Transitional Countries: Fact Book Summarizing Results from Studies Reported between 1990 and 2006. Geneva: World Health Organization.

[29] Yee, B. (2004) Cultural Factors and Health. Encyclopedia of health and behaviour. SAGE Publications. 